Encontro Nacional de

Economia Industrial e Inovação
Indústria e Desenvolvimento Econômico:

desafios e perspectivas

18 a 20 de setembro de 2018

Uberlândia - Minas Gerais

\title{
AGGLOMERATION ECONOMIES, RELATED AND UNRELATED VARIETY IN BRAZIL
}

Jaqueline Moraes ${ }^{1}$

Ivette Luna ${ }^{2}$

\begin{abstract}
This paper aims to analyze preliminary results that quantify and qualify specialization and diversification for Brazilian states on the light of regional economics. For this purpose, it was used RAIS (Annual Relation of Social Information, developed by MTE - Ministry of Labor) and input-output tables. We used the Los index as proxy for specialization and the related and unrelated variety for diversification and found that among the states pointed by this index as more specialized we have Amapá, São Paulo, Paraná and Rio Grande do Sul. On the other hand, the RV and UV indexes showed São Paulo, Paraná, Santa Catarina and Rio Grande do Sul as the ones with higher variety. As conclusion, we identify the necessity of a reevaluation of those indexes at a micro region level, this, due to the continental dimension of the country as well as the high heterogeneity of the Brazilian states. Future research questions are then exposed.
\end{abstract}

Keywords: Regional Economics; Specialization; Diversification; Brazil.

\section{RESUMO}

O objetivo deste artigo é analisar os resultados preliminares que quantificam e qualificam a especialização e a diversificação dos estados brasileiros à luz da economia regional. Para tanto, utilizou-se a RAIS (Relação Anual de Informações Sociais, desenvolvida pelo MTE - Ministério do Trabalho) e tabelas de insumo-produto. Utilizamos o índice de Los como proxy para especialização e a variedade relacionada (RV) e não relacionada (UV) para a diversificação, e descobrimos que entre os estados apontados por este índices como mais especializados são Amapá, São Paulo, Paraná e Rio Grande do Sul. Por outro lado, os índices RV e UV mostraram São Paulo, Paraná, Santa Catarina e Rio Grande do Sul como os de maior variedade. Como conclusão, identificamos a necessidade de uma reavaliação desses índices em nível de microrregião, isto, devido à dimensão continental do país, bem como a alta heterogeneidade dos estados brasileiros. Futuras perguntas de pesquisa são então expostas.

Palavras-chave: Economia Regional; Especialização; Diversificação; Brasil.

ÁREA: 1.4 Padrões de especialização produtiva e desenvolvimento

JEL: P25; R11; O12

\footnotetext{
${ }^{1} \mathrm{PhD}$ Candidate in Economics at UNICAMP. E-mail: jaquelinemagouveia@gmail.com

${ }^{2}$ Professor in the Institute of Economics at UNICAMP. E-mail: iluna@unicamp.br
} 


\section{Introduction}

Regional economics has spent lots of attention in the benefits of local specialization. This is associated with the works of Marshall (1920) and Porter (1990), as long as they were one of the firsts to introduce this type of studies when it comes to regional economics and their structures. This, however, seems to neglect the benefits of a diverse regional economy, which might include stability and external economies.

There is a large debate about specialization and diversification and which one is more conducive to local growth. This has been stimulated by an expressive amount of research about how knowledge spillovers are important for growth (Van Stel and Nieuwenhuijsen (2004), Quatraro (2010) amongst others). As long as knowledge has a large tacit component, they are difficult to codify, thus contacts face-to-face are valuable and the geographical proximity exerts an important role. But these spillovers, these externalities have a degree of relatedness, thus, that is the reason why diversity cannot be measured by a single index.

Although diversification is a well-developed theme in regional economics (Van Stel and Nieuwenhuijsen (2004), Frenken et al. (2007), Boschma and Iammarino (2009), Bishop and Gripaios (2010), Quatraro (2010), Asheim et al. (2011), Boschma et al. (2012a), Boschma et al. (2012b), Kemeny and Storper (2015), amongst others), it hasn't been broadly studied for the Brazilian economy.

This paper aims to fill this gap, contributing to the study of diversification in its both senses: related and unrelated, for all the Brazilian states. Related diversity is observed as an indicative of Jacobs' externalities (Jacobs, 1969), and unrelated variety is an indicative of the portfolio theory. The first is understood as a way to preserve employment, in the sense that the knowledge spillover creates an environment of workers being able to work in all the firms inside the same sectors. Unrelated variety indicates that the demand shocks in one sector cannot be pervasive in all sector, preventing general unemployment to happen.

Besides that, it is relevant to understand the similarity among sectors which is explained by the similarity matrix based on the input coefficients found in the input-output matrix for 2010, considering 67 sectors for the Brazilian economy. This similarity index is used to construct the Los Index (Los, 2000), an index that indicates if the structure of each state is closer to a cluster or more diversified, which is an indicative of localization economies.

Our main research questions are, first, how specialized the Brazilian economy is for 2010, starting from the visualization of the distribution of the Los Index calculated considering a sector-sector and a sector-product approach for qualifying the similarity among sectors. Moreover, we intend to investigate in which measure the Brazilian states are more or less diversified, and if being so, whether they are more diversified towards related or unrelated activities. Furthermore, we expose the Gini Index for all Brazilian states to make a comparison with the unrelated variety measure to first attempt towards the idea that the higher the unrelated variety level in a region, the more equal the income distribution of this region is (Hartmann et al. (2017)), which is the same of saying that the higher the UV the lower the Gini Index.

The paper is divided as follows. After this introduction, we discuss the theoretical framework behind our analysis in the section 2. The analytical framework and the methodology for calculation is discussed at section 3. Section 4 show the maps with the indicators, and a brief analysis of what we found. As concluding remarks, we discuss what we have done, and what we propose as future agenda of research. The references utilized in this paper come in the end.

\section{Agglomeration Economies and Variety: A Theoretical Framework}

Regional economics has been broadly studied with all its aspects and branches being explored. In this sense, one part of the literature has focused in the different types of agglomeration economies and their influence on innovation and regional economic growth. Since the works of Glaeser et al. (1992) and 
Henderson et al. (1995) the debate is specially concentrated in whether regional specialization or diversification promotes innovation, knowledge spillovers and economic growth.

Specialization in the form of localization economies, takes part from the notion of industrial districts from Marshall (1920), and is understood as the sectoral specialization of a region. It forms a specialized labor market, with specialized local suppliers and, more than that, the possibility of knowledge spillovers and the existence of a large market. In this way, the region benefits from the presence of specialized input suppliers and from the local pool of specialized labor skills. Firms, in this sense, learn with each other and there is a cognitive proximity among them, which is supposed to benefit the region with regional economic growth.

Diversification on the other hand can be understood as a plurality of sectors that causes knowledge spillovers in the form of Jacobs' externalities (Jacobs (1970)). The more diversified is a region, the higher is the local growth. This happens because diversity induces knowledge spillovers, triggers new ideas, and provides resources that are required for radical innovation. Economic diversification has a dynamic concept, which means that it is a process of structural transformation, and for Siegel, Johnson and Alwang (1995), it involves resources shift from primary activities to secondary and tertiary sectors.

But some authors like Frenken et al. (2007) understand that the capacity of knowledge to spill over depends on some complementarity among the activities, thus knowledge will spill over only when the cognitive distance among them is not too large (Boschma and Iammarino (2009)). This means that the Jacobs' externalities cover two effects inside one, a knowledge spillover effect and a portfolio effect.

The knowledge spillover effect is known as related variety, sectors that are related in terms of shared complementary competences (Neffke et al. (2011), Rigby (2015)) where some degree of cognitive proximity is needed. It can also be understood as local specialization in related activities inducing innovation and interactive learning. According to Boschma and Iammarino (2009), it goes beyond the definition of localization economies and Jacobs' externalities and gets closer of the Schumpeterian concept of innovation.

It is understood that new activities inside a region are not random events but immersed in territorial capabilities, hence, regional diversification can be understood as an emergent branching process in which those new activities are a recombination of related local activities (Martin and Sunley (2006), Frenken and Boschma (2007), Boschma (2017)).

Related variety includes externalities that may arise from a diversity of related industries inside a region and deals with a delicate choice when it comes to knowledge to spill over effectively among sectors, which is the choice among cognitive proximity and distance across sectors. Thus, the higher the diversity across sectors, the higher the quantity of technologically related sectors and the more the learning opportunities for the sectors in the region. It is about the economic relevance of bringing together different but complementary pieces of knowledge (ASHEIM et al. (2011)).

It is a concept that seeks to link knowledge spillover with economic growth, and if its effects are pervasive it will imply that the long-term development of regions will depend on their abilities to diversify into new sectors concomitantly building on their knowledge bases and competences. Furthermore, related variety has systemic and intangible characteristics, so it is practically impossible to copy and paste sectors in a region which is fully immersed and that depends on resources and assets which are region specific ${ }^{3}$.

Unrelated variety, on the other hand, indicates the diversification of a region in sectors that are not quite related to each other, which means saying that the activities are spread among many different industries. Hence, we can say that those sectors do not share complementary competences and that they do not have a substantial link of economic input-output. Therefore, unrelated variety can be understood as a way to spread risk, as long as it stabilizes the regional economies in the long run.

\footnotetext{
${ }^{3}$ For Boschma (2017), products are considered related when they require similar skills or machines to produce them, which might reflect economies of scope.
} 
It captures the portfolio effect, which means that this kind of diversification works as an absorbent of regional demand shocks, thus, when a region has a large number of industries that are unrelated, the region itself is less vulnerable to demand shocks. The portfolio theory is adapted to this context as a way to understand how a region can spreads risk by diversifying its sectors' portfolio.

The most recent studies, like Permana et al. (2017) and Hartmann et al. (2017), understand that when a region diversify toward unrelated activities it also distributes better the skill premium amongst the workers, which influences the income distribution inside a region. Hartmann et al. (2017) expose that in more diversified economies individuals have more opportunities of learning and of choosing the occupations. This contributes to understand that unrelated variety has more than the portfolio effect but also has the effect of turning the economy more equal. This is part of what the structuralists (Prebisch (1949), Hirschman (1958), and Furtado (1961)) defined as economic development, and part of what would be the overcoming of the underdevelopment for Latin America.

\subsection{Empirical findings: literature review}

Many studies (Van Stel and Nieuwenhuijsen (2004), Frenken et al. (2007), Boschma and Iammarino (2009), Bishop and Gripaios (2010), Quatraro (2010), Boschma et al. (2012b), Kemeny and Storper (2015)) have been dealing with this subject, as well as with this branch line which considers the diversification as related or unrelated.

Van Stel and Nieuwenhuijsen (2004) seeks to answer two main questions, the first is if knowledge spillover emerges primarily inside a sector (intra-sectoral) or among different sectors (inter-sectoral), the second is if local competition has an influence over innovative capacity and economic growth in the regions. For studying this, they use 40 Dutch regions, which include the entire Netherlands, from 1987 to 1995. They seek to examine three possible determinants for regional growth: specialization, diversification, and competition. For the authors, specialization facilitates spillovers inside the same sector (intra-sectoral), diversification, on the other hand, facilitates spillovers among different sectors (inter-sectoral) and competition is a trade-off among internalization of the innovation externalities and the necessity to innovate in order to compete.

They expose three main theories about knowledge spillover and competition. The MAR theory (which stands for the initial of Marshall (1920), Arrow (1962) and Romer (1986)), considers that regional economic growth is maximized when a sector is dominant in the region and the competition is not too strong; the Porter (1990) theory, that agrees with the MAR theory that knowledge spillovers among specialized sectors, but disagrees when stands that competition has a positive effect over economic growth as long as it accelerates imitation and upgrade innovation; and the Jacobs' theory, that agrees with Porter (1990) about competition but considers that the knowledge spillover is more efficient among firms that have different activities.

When testing these hypotheses, they found no evidence of a positive relationship among specialization and economic growth but found that both competition and diversity positively influence regional economic growth. Therefore, they concluded that competition is more important for the industrial sector and that diversification is more important for the service sector.

Frenken et al. (2007) seek to study the relationship among diversification and regional economic growth when considered the agglomeration economies - Jacobs' externalities and localization and urbanization economies - and the portfolio theory at the NUTS 3 regional level. It is exposed that localization economies, in the form of Marshallian externalities, increases the labor productivity as long as it involves a labor market pooling, the presence of specialized suppliers and knowledge spillovers among firms. Urbanization economies happen because more populous places have more agents generating knowledge (besides firms, there will be more consumers, universities etc). Jacobs' externalities increase the opportunities of interaction among firms and stimulate the recombination of knowledge and technologies, which is a form of diversification. 
But the authors also discuss an important issue when it comes to regional economic growth and diversification, which is the differentiation among related and unrelated variety. This differentiation is important because Jacobs' externalities join two kinds of diversification into one, which means that the concept itself can be understood as dealing with two possible events. This diversification can be towards activities that are related with the activities already installed in the region but it can also be towards unrelated activities. And this differentiation is important because it is supposed to affect employment and unemployment in different manners.

Related variety, in the form of Jacobs' externalities, are supposed to affect positively the regional employment growth. Unrelated variety, by the other hand, is supposed to negatively affect regional unemployment growth, because it is understood as an application in portfolio, which protects regional employment from specific demand shocks. This purpose is important when the authors try to explain how diversity, specialization and urbanization can affect employment, productivity and unemployment growth.

In order to do this, they calculate several indexes: ones for qualifying related and unrelated variety both based on an entropy measure; the Los Index as a proxy for localization economies; and population density to capture the urbanization economies' effect. They found that related variety indeed is the responsible for job creation, and that the unrelated variety is indeed negatively related to the unemployment growth, but they found no statistical validity of the relationship among the Los Index (as a proxy for localization economies) and regional productivity growth.

Boschma and Iammarino (2009) study the relationship among related variety, trade linkages and regional economic growth for Italy from 1995 to 2003. They use the strategy developed in Frenken et al. (2007) and calculate indexes for related and unrelated variety, but they do this with data of exporting sectors, while Frenken et al. (2007) use data for some specific sectors (knowledge intensive services and industrial sectors). This difference matters because Boschma and Iammarino seek to understand trade linkages, thus they understand that amongst exporting sectors it is supposed to be a higher outflow of knowledge from a region and also that these sectors are the most apt to absorb, adapt and recombine knowledge. They found strong evidence to infer that related variety contributes to economic growth and that regional economic growth is not affected by the fact that the region has a wide and good relationship with the outside world neither by the high variety of knowledge flows coming from the outside, but it is affected by the relatedness of the extraregional knowledge. This means that this knowledge creates real learning opportunities and contributes to regional employment growth.

Bishop and Gripaios (2010) seek to study how the externalities affect regional employment growth for sub regions of Great Britain from 1995 to 2002 using employment data at the two-digit level of disaggregation from the 1992 Standard Industrial Classification (SIC) for 23 sectors. The authors use the relatedness, competition (measured as the scale effect), cross-boundary spillovers and spatial correlation in order to understand how all of these concepts impact regional growth. It is exposed that spillovers occur within industries (localization economies), across different industries (Jacobs' externalities) and associated with population (urbanization economies). Finally, the conclude that each kind of externalities has a theoretical effect over growth, and also that distinction should be made among related and unrelated variety (following what was exposed in Frenken et al. (2007)).

Spatial proximity and relatedness enhance spillover but unrelated variety is less likely to generate it as long as it is unlikely to yield direct benefits when it comes to employment and productivity, thus it can be seen as an important way to enhance local stability and a protection from sector-specific demand shocks. This spatial proximity leads the authors to add the idea of spatial extent, which means to consider that spatial units can be affected by others because it is complicate to define the area over which spillover effects occur. The authors also understand that different sectors benefit in different ways from diversification.

They estimate an Ordinary Least Squares (OLS) and a maximum likelihood spatial model and found that specialization has generally negative impact on growth, strong local competition has positive effect and diversity has a heterogeneous impact across sectors. Unrelated variety is insignificant for 15 sectors, 
which means that it is really unlikely to generate employment growth but for 8 others, this variable is significant, thus, sectors are not homogeneous. Furthermore, related variety has a significant sign for only 4 sectors, and the signal is not consistent, hence it fails to support the theory that related variety stimulates employment growth. For urbanization economies, they found no consistence for the sign and significance meaning that either urbanization economies are not significant or are offset by diseconomies of urbanization. One possible explanation for the possibility of diseconomies is the congestion of large urban areas.

Quatraro (2010) seeks to bring technological knowledge into an empirical framework, analyzing the determinants of cross-regional differential growth rates, thus the author tries to examine the effect of the knowledge dynamics over the evolution of the manufacturing sector in Italian regions from 1981 to 2002. The author explains technological knowledge as being the outcome of a combinatorial search activity which is carried out across a technological space. At this space, there is some combinable elements. By doing this, the author can describe the internal structure of the regional knowledge base that goes beyond the idea of knowledge stock. Empirical estimations indicate that knowledge coherence and knowledge variety matter when it comes to regional economic performances. Moreover, spatial dependence is checked and suggests that cross-regional externalities, although trigger additional effects on growth, do not debase the effects of knowledge properties.

Boschma et al. (2012b) study the effect of related variety and other spatial externalities over regional economic growth in Spain at the NUTS 3 regional level from 1995 to 2007. They use a cluster classification to determine relatedness across products and a measure based on the proximity indicator developed by Hidalgo et al. (2007). They calculate these two novel indicators to contrast with the standard measure of relatedness based on product classifications, thus they also calculate this one in order to confirm the merits of the new ones. They found that related variety matters when it comes to growth across regions. Moreover, they found that Spanish provinces with a broader range of related activities tend to show higher rates of economic growth.

Kemeny and Storper (2015) study whether it is better for a region to be highly specialized or diversified. For them, in terms of trade and growth of external demand, a favorable specialization pattern is good for the economy of the region. The authors explain that some arguments that defend the virtues of diversification, like the spreading of the risk, that urbanization economies supply general inputs at efficient scales that are useful to many activities in a region and the 'mix and match' view of the dynamics of economic development, does not take into account that diversification has opportunity costs, which could deprive an economy of benefits that could arise from specialization. More than that, the authors expose that for being big and diversified, a city might have become big by being specialized, in the first place.

The authors make an important distinction among relative and absolute specialization. Relative specialization has to do with shares, which means, an industry's employment share in some activity. In absolute terms, specialization means when a region has a particular activity which is a source of many jobs or a high level of output or large number of firms. Theoretically speaking, the case of specialization based on absolute size is considered the more visible and it affects the region's productivity by sharing of input suppliers, matching of specialized labor demand and supply and technological learning or spillovers.

According to them, when it comes to relative specialization, the economic benefits that may arise from it has to do, first, with the competition among the firms, in a way that would raise competition for factors and resources but would also stimulate technological progress and sophistication and the region's productivity, as well. Furthermore, it is helpful on leading the regional economy to a dynamic path, as long as it creates dynamic industry groups and a functioning ecosystem.

Kemeny and Storper (2015) rise the important differentiation that is made by Frenken et al. (2007), which is the one of related and unrelated variety. When considering that economies develop through recombination, they state the question if they are recombining inputs from sectors that are related, or 
somehow close neighbors in terms of technology and knowledge base, or if they are doing this by recombining different, unrelated things, and hence benefiting from diversification.

The authors seek to explain the average wage of workers when it is considered the level of relative and absolute specialization, amongst some other variables, and find that the level of absolute specialization is indeed positive and significantly related to the wage. When considered the relative specialization, it is not significantly associated with wage's dynamics.

\section{Analytical Framework}

This section aims to exposes the indexes to analyze relatedness in this paper were calculated and how they can be interpreted. All of these measures were calculated based on Frenken at al. (2007) with minor adaptations for the Brazilian economy. The most expressive adaptation is the use of sectors at fourdigit levels of disaggregation of the National classification of economic activities (CNAE 2.0) - compatible with ISIC Rev3 classification - rather than the five-digit level. Moreover, we made no arbitrary choice of sectors for the calculation of the Los Index and decided to apply the measure for all sectors besides expanding the analysis for a more specific relationship among sectors and products they use as input.

\subsection{Localization Economies}

As a proxy of localization economies, we follow Los (2000), as exposed in Frenken et al. (2007) and used the Los-Index. It is assumed that localization economies are somehow associated with the concentration of a particular sector inside the region. In order to measure this, we compute the technological similarity among two sectors based on the 2010 Brazilian input-output tables ${ }^{4}$.

Considering that input combinations are capable of measure the production technologies, we can assume that the higher the similarity among the inputs of two sectors, the smaller the technological distance will be and the higher the resultant spillover. Therefore, the similarity among the same sector equals unity.

No arbitrariness was performed in the choice of sectors, thus we applied the measure for all sectors presented in the national input-output table as a first attempt to construct the index for the Brazilian case, which consists of 67 sectors, as presented by the Sistema de Contas Nacionais (SCN), and considers only formal workers attached to each sector, as presented in Relação Anual de Informações Sociais (RAIS), created by Ministério do Trabalho e Emprego (MTE) which considers only formal workers and the classification CNAE 2.0 (Classificação Nacional de Atividades Econômicas).

At this point a translation was needed, as long as RAIS categorizes sectors by CNAE classification and the input-output matrix uses the classification by SCN. Although it is not a perfect translation, care was taken to make it in the best way possible.

Furthermore, we applied the same measure for the analysis of a sector-product interaction, which means that - different from the paper that guides this research - we also considered the relationship among the 67 sectors with the 128 products that can be used as input. We believe that an approximation of the sectoral technological recipes based on shares of products rather than shares of inputs by sectors provides a better estimate of a modal technology and hence, allows us to build a better proxy for the similarity index.

Initially, we need to considerer that the column of an input coefficient matrix that arises from the input-output table is a simplified version of the sector's technology. After considering this, similarity measures among two sectors' production technologies can be estimated from this column.

The cosine similarity among a pair of input coefficient vectors is:

\footnotetext{
${ }^{4}$ It is necessary to emphasize that the results presented here were the results available until the act of submission, however, new efforts are being made to first increase the temporal cut, as well as the spatial analysis.
} 
$\omega_{i j}=\frac{\sum_{k=1}^{n} a_{i k} a_{j k}}{\sqrt{\sum_{k=1}^{n} a_{i k}^{2} \sum_{k=1}^{n} a_{j k}^{2}}}$

where $\omega_{i j}$ represents the similarity index among sectors $i$ and $j$; with $i, j=1, \ldots, n$; $n$ is the total number of sectors (or products) from the input-output tables and $a_{i k}$ and $a_{j k}$ denote the vectors of inputs.

Therefore, the Los-Index can be calculated as follows:

$\operatorname{Los}_{k}=\frac{\sum_{i=1}^{n} \sum_{j=1}^{n} s_{i k} s_{j k} \omega_{i j}}{\sum_{i=1}^{n} \sum_{j=1}^{n} s_{i k} s_{j k}}$

where $s_{i k}$ and $s_{j k}$ stand for the number of jobs in sectors $i$ and $j$, respectively; and $k$ represents the region for which the index is calculated. In this first attempt we opted for doing the calculations for every state of the federation.

This measure is used both, to calculate the similarity among each pair of sectors as for the interaction among the sector and the product used as input made by the other sector. A state that is fully specialized in just one sector has the maximum possible value for the index, 1. For the other cases, the index is going to range among the minimum value $(1 / n)$ and the maximum (1). The maximum value, 1 , indicates that the region has a type of cluster in a determined sector, or that it has a set of technologically equivalent sectors.

\subsection{Jacobs' externalities}

As a proxy for diversified economies, we constructed two variables that could measure both the related and the unrelated varieties. We used, following Frenken et al. (2007), the entropy measure, which has, one of many advantages, the possibility of being decomposed at each sectoral digit level. Data of Brazilian states for 2010 were extracted from the RAIS.

Initially, let all four-digit sectors $i$ fall under a two-digit sector $S_{g}$, where $g=1,2,3 \ldots G$. In this way, we can measure the two-digit shares, $P_{g}$, by summing up the four-digit shares, $p_{i}$. Each $P_{g}$ shows the participation of the five-digits level sector inside the two-digits sectors. Therefore, we have:

$P_{g}=\sum_{i \in S_{g}} p_{i}$

For the related variety, we measured the weighted sum of the entropy indicator at the four-digit level within each two-digit level. Entropy here can be understood as a measure of inequality or diversity. Therefore, given that we are looking inside a specific two-digit sector and how it is composed from its four-digit sectors, the more diverse they are, the lower the entropy will be.

So, if the related variety is high, it is assumed that the sectors at the four-digit level that share the same two-digit level class understand each other because they are more similar. As a consequence, the more the related variety we find within each four-digit level inside the same two-digit level class, the more opportunities for learning, for knowledge spillovers. Also, since this index is calculated for every Brazilian state, the more the variety, the more the state will benefit for these sets of different, although related, sectors. From what was exposed, the related variety index (RV) is given by

$R V=\sum_{g=1}^{G} P_{g} H_{g}$

where:

$H_{g}=\sum_{i \epsilon S_{g}} \frac{p_{i}}{P_{g}} \log _{2}\left(\frac{1}{p_{i} / P_{g}}\right)$ 
This way, we understand related variety for each Brazilian state by summing up the degree of related variety for each two-digit class in a state. The higher the RV indicator, the higher is the knowledge spillover and the higher it is supposed to be the regional economic growth.

For unrelated variety, we measured the entropy of the productive structure at a two-digit level. This indicator shows in which extent a state is characterized by different types of sectors. Therefore, the more variety at the two-digit level the more a state is endued with different sectors and it should be understood as the measure of the portfolio effect of the variety.

$U V=\sum_{g=1}^{G} P_{g} \log _{2}\left(\frac{1}{P_{g}}\right)$

The next section explores the results obtained with these metrics and exposes the discussion that arises from the analyses.

\section{Results and discussion}

The objective of this section is to explore the indexes that were calculated for the Brazilian economy for 2010. At this point, it is important to assert that all the analyses are exploratory rather than confirmatory. It is the first attempt to calculate region-specific measures, based on region-specific databases and with a look for the Brazilian economy and its heterogeneity. It is important to mention that, as long as Brazil is a country full of specificities and particularities, no a priori analyses or "one-size-fits-all" policies, that cannot handle such specificity, should be used to identify it.

The maps exposed below give us the visual distribution of the indexes that were calculated for all Brazilian states plus the Federal District, Brasília. Figure 1a shows the Los Index when we consider the relationship among sector-sector (LOS_SS). Figure 1b shows the relationship among sector-product (LOS_SP). Figure 2a shows the related variety measure (RV) and Figure $2 \mathrm{~b}$ shows the unrelated variety measure (UV). Figure 3a gives us additional information about the population and Figure $3 \mathrm{~b}$ shows the Gini Index for all Brazilian states for 2010.

Considering initially the Los Indexes, it can be inferred that, when we analyze the broader relationship among sector-sector (Figure 1a), states like Amazonas, Roraima, Amapá, Maranhão and Rio de Janeiro show the highest levels of specialization, indicating that these states have some activity in which they are specialized. This result is especially visible when it comes to Amazonas, when we consider Manaus Free Trade Zone. But when we decompose the relationship among sector-product (Figure 1b), which gives a more disaggregated vision about the regions' dynamics, the picture changes, indicating that the states that are more specialized are actually Amapá, São Paulo, Paraná and Rio Grande do Sul. The question that remains is why these changes occurs? One possible explanation is that the biggest decomposition allows to verify more deeply the kind of specialization that is possibly occurring.

The difference between the two indexes can also be a result of a greater detailing to qualify the technologies of the sectors from the sector-product matrices if compared to the smaller detail that we have of this modal technology of the sectors when we use the sector-sector tables. Given the vast diversity of the country and each of its states, we noticed a greater diversity when looking at LOS_SP (Figure 1b). This can be understood as an indicative that at least for Brazil, using this matrix (sector-product) would be better, even if for other studies in the literature the use of sector-sector matrices is sufficient. 


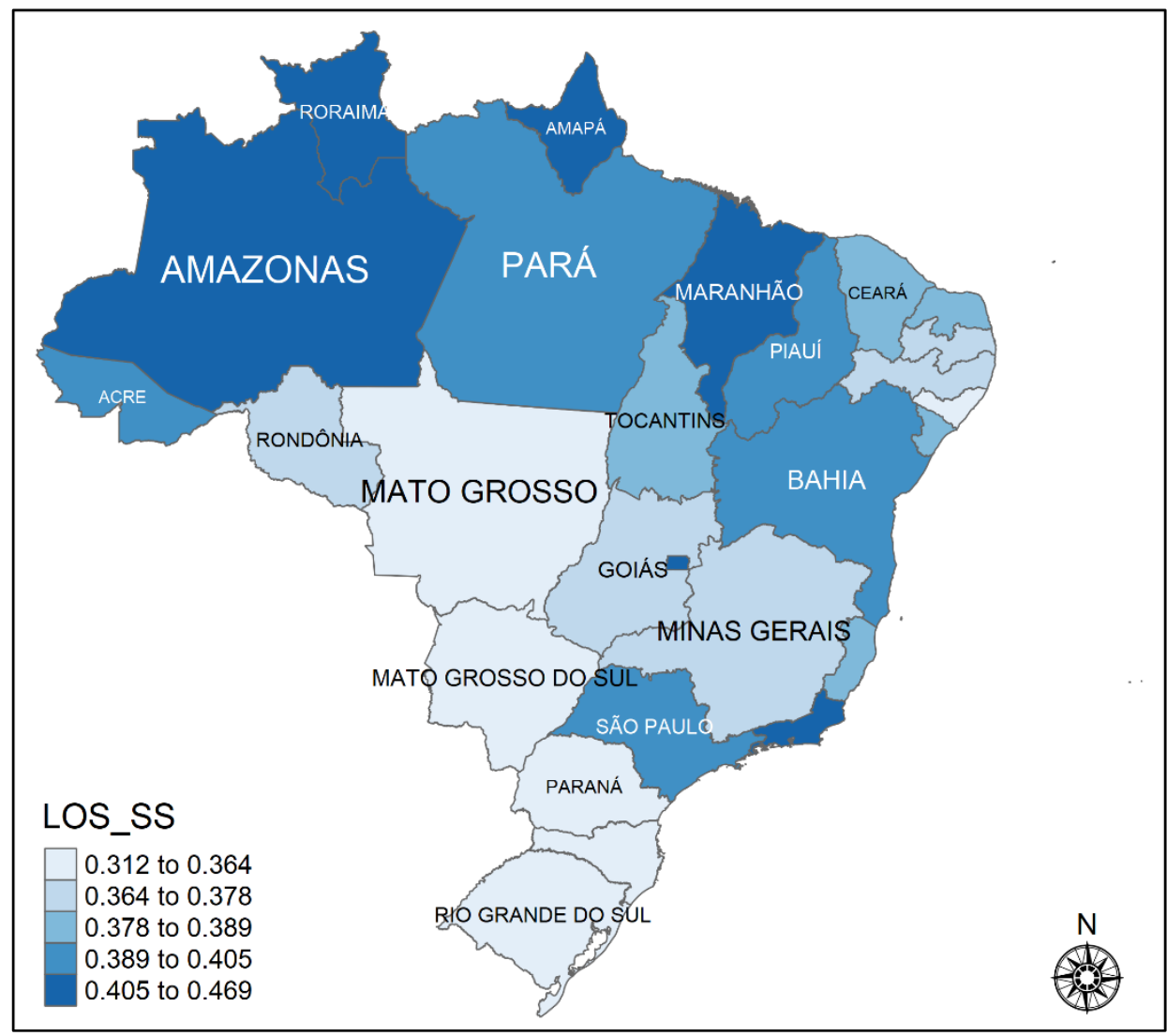

FIGURE 1a: Map of the Los Index Sector-Sector(LOS_SS) for all Brazilian states for 2010.

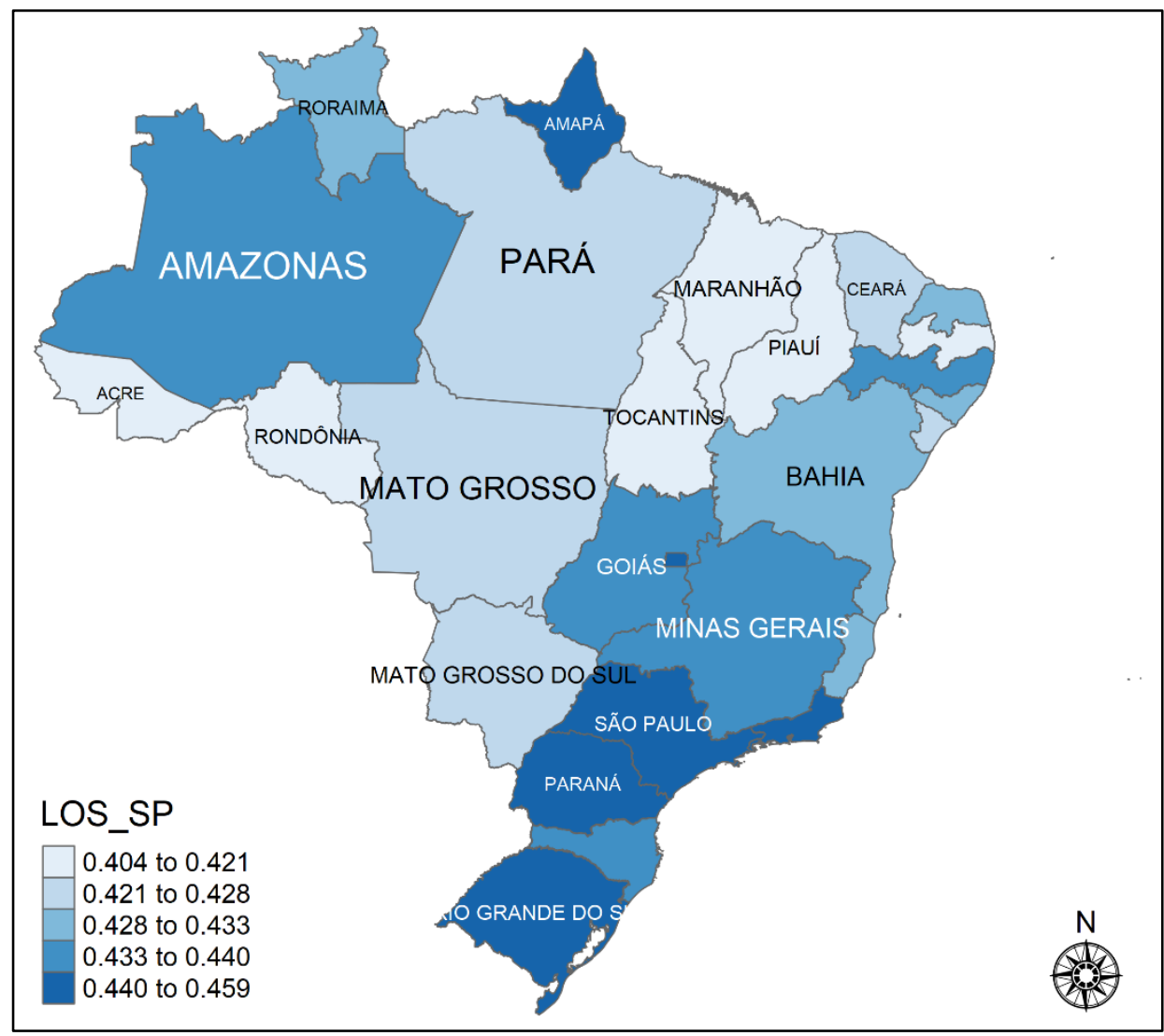

FIGURE 1b: Map of the Los Index Sector-Product (LOS_SP) for all Brazilian states for 2010. 
From Figure 2a we can also see that the states of Goiás, Minas Gerais, São Paulo, Paraná, Santa Catarina and Rio Grande do Sul have a higher level of related activities than the other states. This map of RV also seems to indicate the idea of the Brazilian industrial polygon developed by Diniz $(1993)^{5}$, although all sectors had been included in the measurement. As long as it is possible to specialize in related activities, the map of related variety might help to throw a light in this matter, making more understandable the map of the Los Index sector-product (Figure 1b).

About the UV map in Figure 2, it is possible to see that Minas Gerais, São Paulo, Paraná, Santa Catarina and Rio Grande do Sul have the highest levels of unrelated activities, and this seems to contradict the information that is exposed about the RV. One possible explanation is that these measures, calculated for Brazilian states, hide some important facts about the regional economy.

The RV index looks inside each sector at two-digits level and observes the diversity between sectors at four-digits levels that makes up each sector at two-digits level. Therefore, a sector with high RV implies that there is a great diversity within this sector and, therefore, there are all the positive impacts of knowledge spillovers and knowledge diffusion among sectors. On the other hand, even if a single two-digits sector is quite diverse (in the related sense, since all are within the same large sector), if the UV is low, there are few enough two-digits sectors in the industry to consider that there is a great diversity (unrelated).

Therefore, RV and UV in the same state can be high. This is the case of São Paulo, for example. The diversity / heterogeneity within each two-digits sector is high, but there is also a productive diversification at the two-digits level. That is, there is a persistent diversity that favors the state in two important ways (the related and unrelated). And it is worth considering that, differently of what was observed in Frenken et al. (2007), there is already an indication that at least for Brazil, RV and UV are high for the same regions, which is not the case in the Netherlands.

\footnotetext{
${ }^{5}$ For Diniz (1993), the polygonal development of the regions is a result of five representative forces: diseconomies of agglomeration of the state of São Paulo and the creation of economies of agglomeration in other states; the role of the Government by conceding fiscal incentives and by stimulating the construction of infra structure; the natural resources that stimulated the search for other regions in order to develop; the income concentration social and spatially; and the market unification that contributed to the geographical deconcentrating of the production.
} 


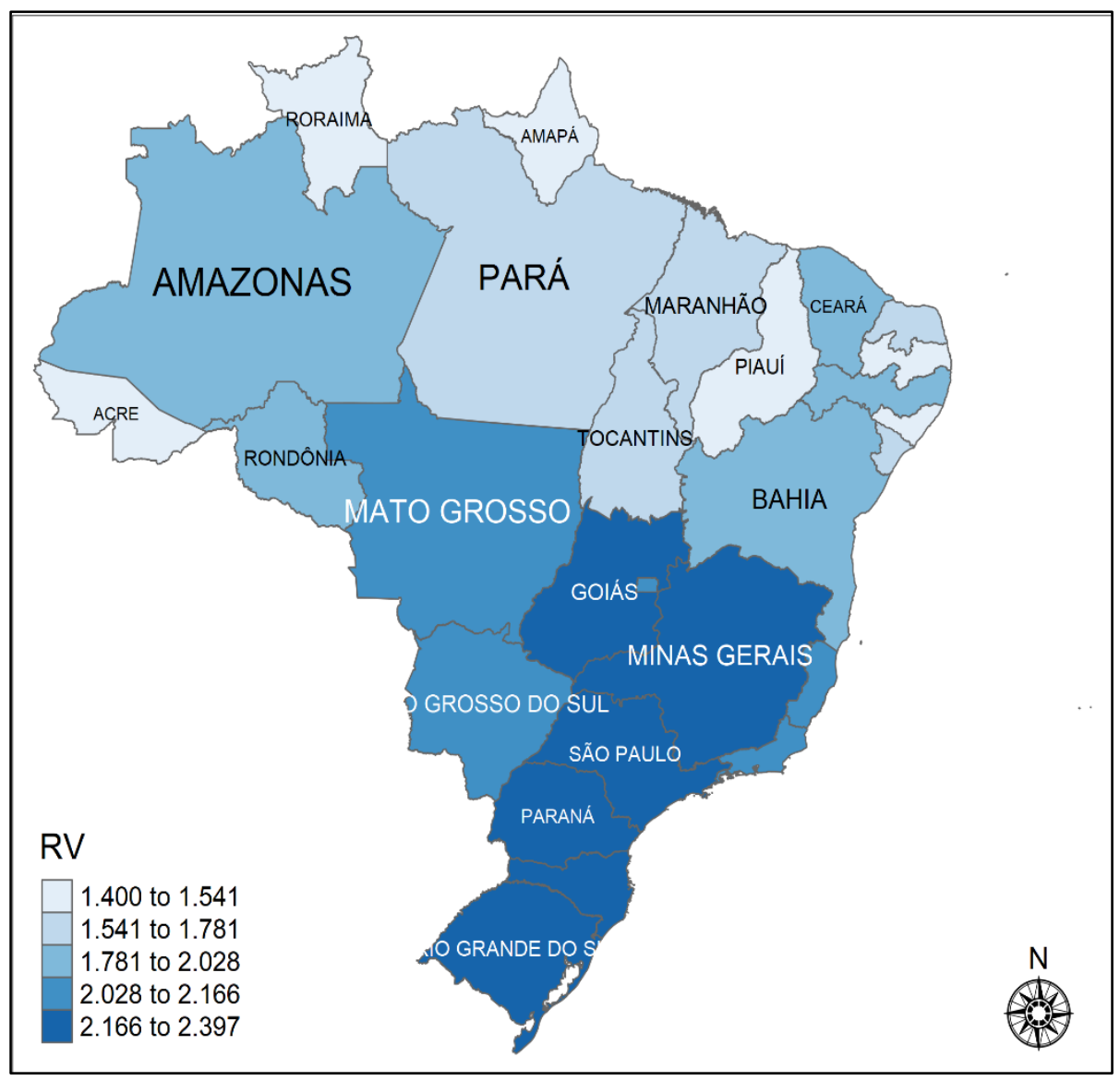

FIGURE 2a: Map of the index of Related Variety (RV) for all Brazilian states for 2010.

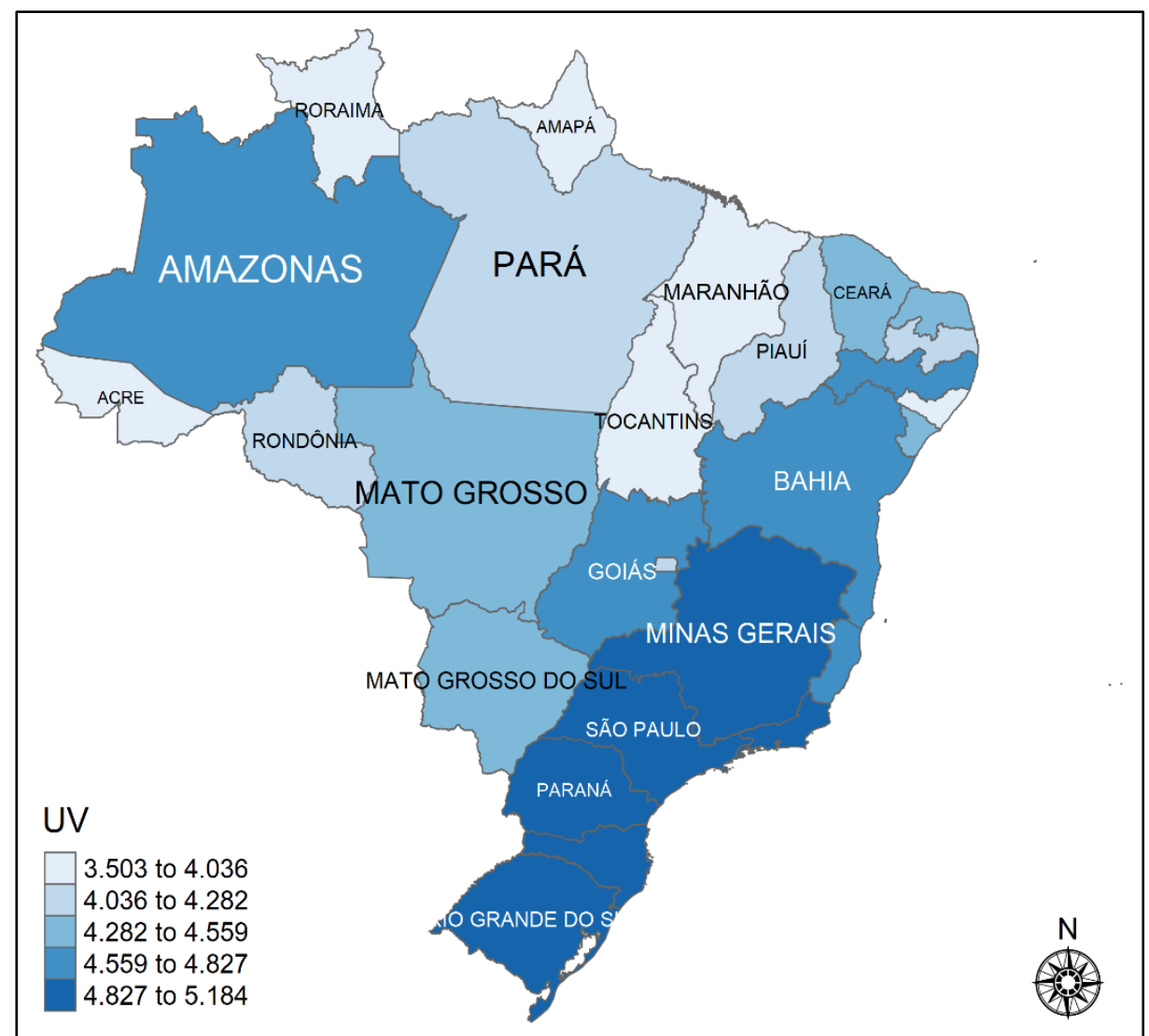

FIGURE 2b: Map of the index of Unrelated Variety (UV) for all Brazilian states for 2010. 
Using the additional maps from Figure 3a below, it is possible to infer that the argument of Siegel et al. (1995) can be right for the Brazilian economy, which is that there is a positive relationship among the population and the diversity of a region. When attention is paid to the size, in terms of population, of Minas Gerais, São Paulo, Bahia, Paraná and Rio Grande do Sul, it is possible to verify that these states are also the states with high levels of diversification, in its broad sense (related and unrelated). Then, how the size of a region is conditioning its opportunities as long as diversification is a path dependent process? Moreover, this involves migration questions, considering that Brazil has a high level of internal migration across states, which also might be influencing the productive structure of regions.

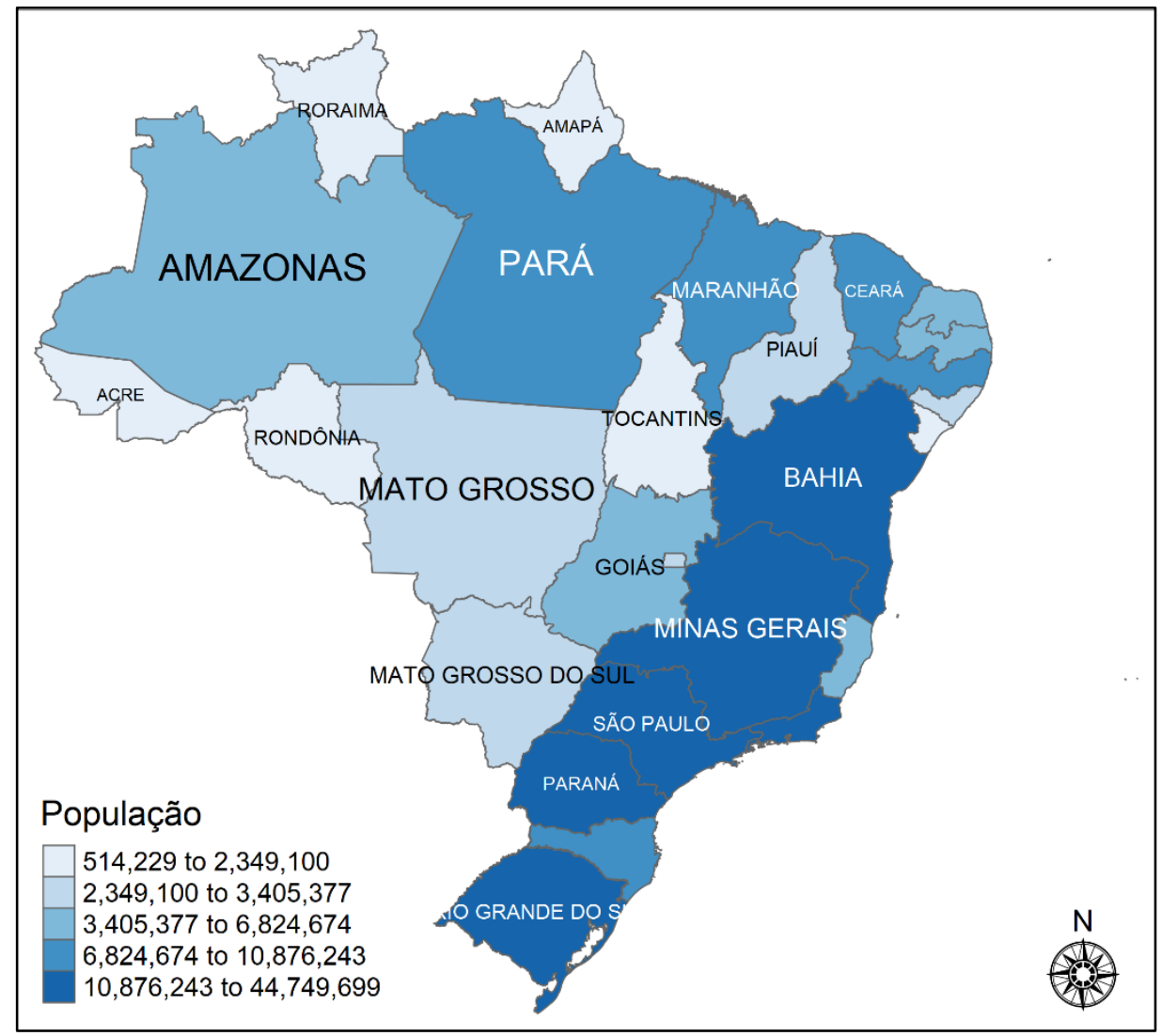

FIGURE 3a: Map of the Brazilian population for all Brazilian states for 2010.

And by taking Figure 3b, we considered the Gini Index for all Brazilian states for 2010, in order to give a first sight at another question, which is if for the Brazilian states it is valid the idea that the higher is the diversification towards unrelated activities the lower is the income inequality. Giving a look at the map, it can be inferred that the Gini Index seems to reflect a lower inequality the higher is the index of the states (see the map of UV in Figure 2b). It is clear that this is just a first attempt to verify this relationship, thus nothing can be affirmed. Moreover, it is intended to explore this exact relationship in future works, following Hartmann et al. (2017). 


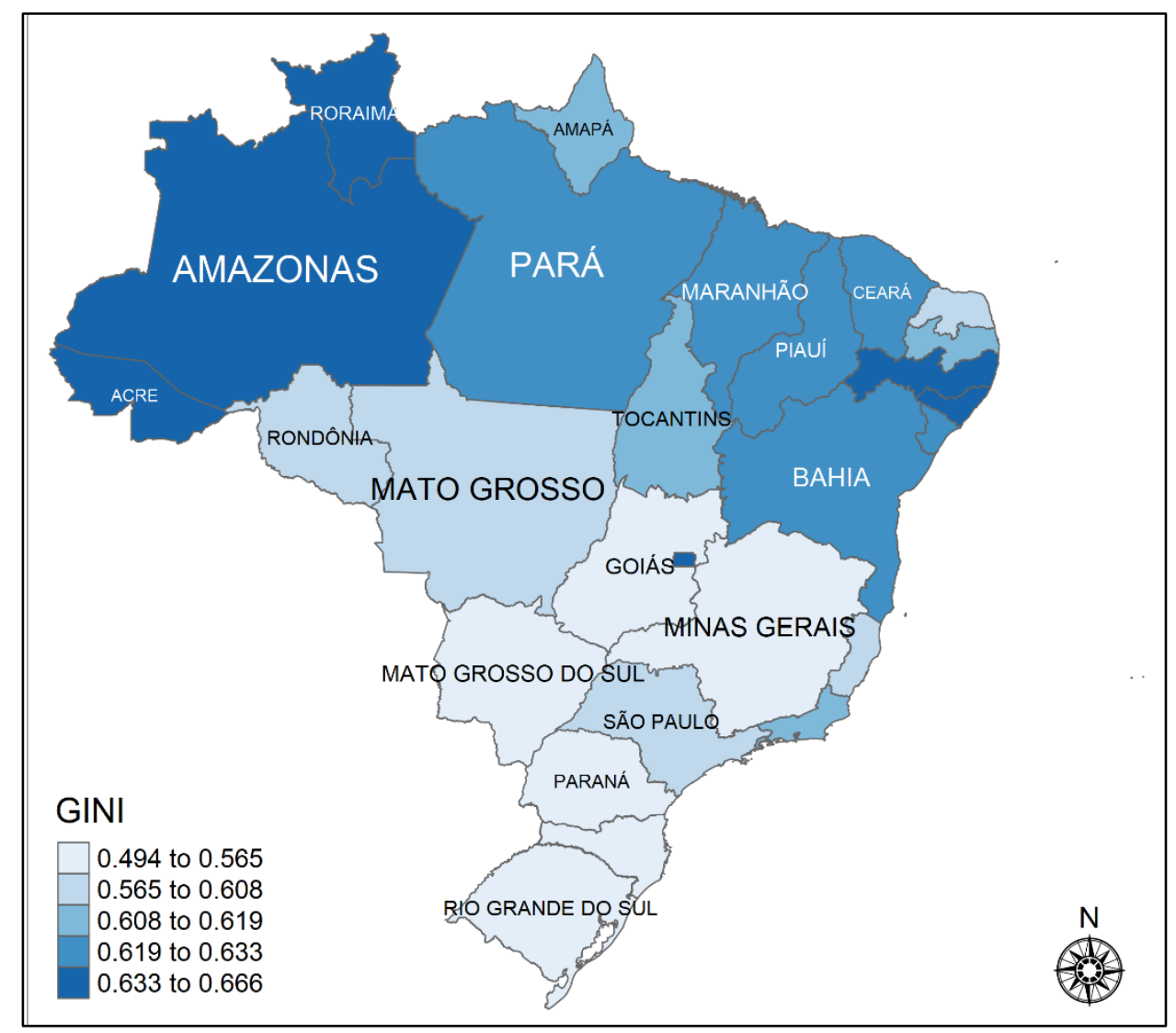

FIGURE 3b: Map of the Gini index for all Brazilian states for 2010.

Most part of the Brazilian states seem to have a mix in their activities, as long as some of them have higher levels of related and unrelated variety as well. This justifies the need to understand better the heterogeneities that happen inside Brazil by studying these indexes for micro regions. An analysis for states is a first indicative of how is structured the Brazilian economy, when it comes to specialization and diversification. But is hides some important information, like if a state has micro regions which have totally different profiles, if unrelated activities are indeed tied to micro regions with higher levels of human capital available, if micro regions with higher levels of related variety have a more asymmetric income distribution, as long as it creates a demand only for high skilled labor forces.

\section{Concluding remarks: what is next?}

This paper presents preliminary results from our first attempt to quantify and qualify specialization and diversification for Brazilian states on the light of regional economics. After a meticulous data processing and analysis of a set of databases - including RAIS and input-output tables - we use the Los index as proxy for specialization and the related and unrelated variety for diversification, all those based on a well stablished literature in the field of Geographic Economics.

Our results showed the need of considering a reevaluation of those indexes at a micro region level, this, due to the continental dimension of the country as well as the high heterogeneity of the Brazilian states. In terms of specialization the Los index also suggests that, at least for the Brazilian case, it is more suitable to use the sector-product relationship to qualify the interaction among sectors and their respective modal technologies. Among the states pointed by this index as more specialized we have Amapá, São Paulo, Paraná and Rio Grande do Sul. On the other hand, the RV and UV indexes showed São Paulo, Paraná, Santa Catarina and Rio Grande do Sul as the ones with higher variety. Finally, if those measures are correlated with the Gini index, at least at a first sight we can infer that in fact, as stated in the literature, there is evidence of diversification contributes to the reduction of income inequality, although we need to go further into our research in order to do any affirmation. 
Thus, some questions arise from all that have been discussed in this paper: In which measure these results affect employment growth in Brazilian micro regions? For Brazil, unrelated variety can actually soft unemployment growth? For related activities it is understood that knowledge flows between them, but do the workers also flow equally? The internal human capital migration has doomed the productive structure of the micro regions? It is stated that the higher the populational density the lower is the unemployment rate (Frenken et al. (2007)), is this true for Brazil even when we consider the emigration flux inside our country? Furthermore, the higher the UV measure, the lower is the income inequality for micro regions in Brazil? How diversification in micro regions can be related with poverty inequality within them? Those micro regions with higher UV level is the ones with better income distribution, as long as it distributes better the skill premium for high skilled labors? Last but not least, RV and UV affect employment and unemployment in the same magnitude and direction all job occupations? All of these questions are part of a research agenda.

\section{References}

Asheim, B. T., Boschma, R., Cooke, P., 2011. Constructing regional advantage: Platform policies based on related variety and differentiated knowledge bases. Regional studies 45 (7), 893-904.

Bishop, P., Gripaios, P., 2010. Spatial externalities, relatedness and sector employment growth in Great Britain. Regional Studies 44 (4), 443-454.

Boschma, R., 2017. Relatedness as driver of regional diversification: A research agenda. Regional Studies $51(3), 351-364$.

Boschma, R., Frenken, K., Bathelt, H., Feldman, M., Kogler, D., et al., 2012a. Technological relatedness and regional branching. Beyond territory. Dynamic geographies of knowledge creation, diffusion and innovation, 64-68.

Boschma, R., Iammarino, S., 2009. Related variety, trade linkages, and regional growth in Italy. Economic geography 85 (3), 289-311.

Boschma, R., Minondo, A., Navarro, M., 2012b. Related variety and regional growth in Spain. Papers in Regional Science 91 (2), 241-256.

Diniz, C. C., 1993. Desenvolvimento poligonal no Brasil: nem desconcentração, nem contínua polarização. Nova Economia 3 (1), 35-64.

Frenken, K., Boschma, R. A., 2007. A theoretical framework for evolutionary economic geography: industrial dynamics and urban growth as a branching process. Journal of economic geography 7 (5), 635649.

Frenken, K., Van Oort, F., Verburg, T., 2007. Related variety, unrelated variety and regional economic growth. Regional studies 41 (5), 685-697.

Furtado, C., 1961. Desenvolvimento e subdesenvolvimento. Estante de Economia.

Glaeser, E. L., Kallal, H. D., Scheinkman, J. A., Shleifer, A., 1992. Growth in cities. Journal of political economy 100 (6), 1126-1152.

Hartmann, D., Guevara, M. R., Jara-Figueroa, C., Aristarán, M., \& Hidalgo, C. A., 2017. Linking economic complexity, institutions, and income inequality. World Development, 93, 75-93.

Henderson, V., Kuncoro, A., Turner, M., 1995. Industrial development in cities. Journal of political economy 103 (5), 1067-1090. 
Hirschman, A. O., 1958. The strategy of economic development.

Jacobs, J., 1969. The economies of cities. Jonathan Cape.

Kemeny, T., Storper, M., 2015. Is specialization good for regional economic development? Regional Studies 49 (6), 1003-1018.

Los, B., 2000. The empirical performance of a new inter-industry technology spillover measure. Technology and Knowledge 118, 151.

Marshall, A., 1920. Principles of Economics: An introductory volume. Macmillan London.

Martin, R., Sunley, P., 2006. Path dependence and regional economic evolution. Journal of economic geography 6 (4), 395-437.

Neffke, F., Henning, M., Boschma, R., 2011. How do regions diversify over time? Industry relatedness and the development of new growth paths in regions. Economic Geography 87 (3), 237-265.

Permana, Y., Castaldi, C., Nomaler, Z. O., Alkemade, F., 2017. Innovation, technological variety and income inequality: evidence from EU regions. In 10th European Meeting on Applied Evolutionary Economics (EMAEE 2017), May 31-June 3, 2017, Strassbourg, France: Creativity, Innovation and Economic Dynamics.

Pinheiro, F. L., Alshamsi, A., Hartmann, D., Boschma, R., Hidalgo, C., 2018. Shooting Low or High: Do Countries Benefit from Entering Unrelated Activities?

Porter, M.E., 1990. The Competitive Advantage of Nations Free Press, New York.

Prebisch, R., 1949. El desarrollo económico de la América Latina y algunos de sus principales problemas. El trimestre económico, v. 16, n. 63, p. 347-431.

Quatraro, F., 2010. Knowledge coherence, variety and economic growth: Manufacturing evidence from Italian regions. Research Policy 39 (10), 1289-1302.

Rigby, D. L., 2015. Technological relatedness and knowledge space: entry and exit of us cities from patent classes. Regional Studies 49 (11), 1922-1937.

Siegel, P. B., Johnson, T. G., Alwang, J., 1995. Regional economic diversity and diversification. Growth and Change 26 (2), 261-284.

Van Stel, A. J., \& Nieuwenhuijsen, H. R., 2004. Knowledge spillovers and economic growth: an analysis using data of Dutch regions in the period 1987-1995. Regional Studies, 38(4), 393-407. 